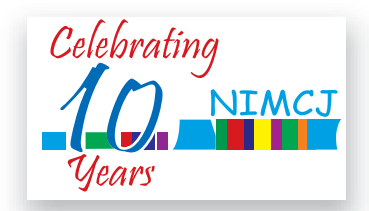

${ }^{1}$ Dr. Farzana Rahman Chowdhury MBBS, FCPS (Pediatrics) Assistant Professor Dept. of Pediatrics Popular Medical College, Dhanmondi, Dhaka

${ }^{2}$ Prof. Dr. B.H. Nazma Yasmeen MBBS, MCPS (Pediatrics) MD (Pediatrics) Professor and Head Dept. of Pediatrics Northern International Medical College, Dhaka

${ }^{3}$ Dr. Shabnam Rahman MBBS, FCPS (Gynae \& Obs) Assistant Professor Dept. of Gynae and Obs. Enam Medical College, Savar, Dhaka

Correspondence

Dr. Farzana Rahman Chowdhury MBBS, FCPS (Pediatrics)

Assistant Professor

Dept. of Pediatrics

Popular Medical College,

Dhanmondi, Dhaka

e-mail: shomi9@yahoo.com

\title{
Study on Exclusive Breastfeeding practice and related factors among mothers attending in a tertiary care hospital of Bangladesh
}

\author{
F R Chowdhury ${ }^{1}$, B H N Yasmeen ${ }^{2}$, S Rahman ${ }^{3}$
}

\begin{abstract}
Back ground : Exclusive breastfeeding (EBF) means that the infant receives only breast milk for the first six months of life after birth. In Bangladesh, 55\% of children less than 6 months of age are exclusively breastfed according to BDHS 2014.

Objectives : To assess the exclusive breast feeding practice and associated factors among children in an urban area ofBangladesh.
\end{abstract}

Method : This cross-sectional study was conducted in Popular Medical College, Dhanmondi, Dhaka, among 80 mothers having infants aged 7-12 months, attending the outpatient department were selected purposively for the study during the period of 1st August 2017 to 31st December 2017. Sample were selected purpasively for the study and predesigned questionnaire were used for data collection. Data analysis was done by using SPSS software version 22.

Result : It was found that only 30(37.5\%) mother went for regular antenatal checkup and remaining $50(62.5 \%)$ had irregular antenatal check up. But none of them got breastfeeding advice during antenatal visit. Breastfeeding was initiated with in 1 hour of birth in 36(40\%) cases and $44(60 \%)$ cases after 1hour of birth. Exclusive breastfeeding (EBF)was found in $40(50 \%)$ children. Among them $30(75 \%)$ were children of housewife mothers. Mixed feeding (breast milk plus formula/ cow's milk) was given to 30 children among them18 (60\%) were the children of housewife mothers. Only formula milk was given to 10 children of them $8(80 \%)$ were the children of housewife mothers. Exclusive breast milk was not given by $18(45 \%)$ mothers due to job or other occupation whereas $22(55 \%)$ mother did not give EBF due to insufficient breast milk.

Conclusion : In the study rate of exclusive breast feeding was $50 \%$. This study also showed that frequency of exclusive breast feeding practice was lower in working mothers than housewife mothers. This study also showed that the speculation of not getting sufficient milk was one of the main reasons for not giving exclusive breastfeeding.

Key Words : Exclusive breast feeding, antenatal visit.

DOI: $10.3329 /$ nimcj.v10i1.39329

Northern International Medical College Journal Vol. 10 No. 1 July 2018, Page 343-346

\section{Introduction}

Breast milk is the natural first food for babies, it provides all the energy and nutrients that the infant needs for the first 6 months of life and it continues to provide up to half or more of a child's nutritional needs during the second half of the first year and up to one-third during the second year of life. ${ }^{1}$ Breast milk promotes sensory and cognitive development, and protects the infant against infectious and chronic diseases.The World Health Organization (WHO) recommends the practice of exclusive breastfeeding (EBF) of infants for the first six months of life starting from birth. According to WHO exclusive breastfeeding - means that the infant only receives breast milk without any additional food or drink, not even water. Exclusive breastfeeding reduces infant mortality due to common childhood illnesses such as diarrhoea or pneumonia, and helps for a quicker recovery during illness. Studies have demonstrated that it reduces deaths in infants and young children. ${ }^{2,3}$

Globally, suboptimum breastfeeding was responsible for $11.6 \%$ of all child deaths in $2011 .{ }^{4}$ Universal (90\%) coverage of breastfeeding is estimated to prevent around $13 \%$ of all deaths among children under five years of age in low and middle income countries. ${ }^{4}$ However, globally only half of infants under 1 month of age and 30\% of infants aged 1-5 months are exclusively breastfed. ${ }^{4}$ Several 
factors have been shown to be associated with exclusive breast feeding: variations between urban and rural areas, infant's age, mothers' employment status and education level, knowledge about good breastfeeding practices, occupation, monthly household income, mothers' smoking status, socio-economic position, prelacteal feeding, parity, positive attitudes towards exclusive breast feeding, intended to exclusively breastfeed before delivery, timely initiation of breastfeeding, mode of delivery, infant's birth weight, health system practices, discarding colostrum and community beliefs. ${ }^{5}$

The global strategy for infant and young child feeding was approved by World Health Assembly in May 2002 and was endorsed by UNICE. The strategy is supportive of mother and family impacting directly on early childhood survival, growth and development. These feeding practices are known collectively as IYCF practices which includes breastfeeding and complementary feeding. ${ }^{6}$ In Bangladesh, the prevalence of EBF was around $55 \%$ according toBDHS, 2014. Thus to investigate the issue further, this study was conducted. The objective of this study was to find out the practice of EBF and some related factors among mothers having infants aged 7-12 months in an urban area of Bangladesh.

\section{Materials and Methods}

This is a cross sectional study conducted at the outpatient department of Popular Medical College Hospital, Dhanmondi, Dhaka. During the period of $1^{\text {st }}$ August 2017 to $31^{\text {st }}$ December 2017. Total 80 mothers having infants aged 7-12 months interviewed and included consecutively. Sick children requiring emergency care, irritable children and mothers who were unwilling to participate were excluded from the study. All mothers were interviewed after obtaining informed written consent. Predesigned questionnaire were used for data collection. Information's for initiation of breast feeding and exclusive breast feeding were elicited by historic recall.

Early initiation of breast feeding was considered when proportion of children who were put on breast within one hour of birth.

Exclusive breastfeeding was considered when proportion of infants who were fed exclusively from breast from birth up to 6 months (180 days) of age.

Data analysis was done by using SPSS software version 22.

\section{Results}

In this study 80 mothers having infants aged 7-12 months were interviewed, mean age of children in month was 8.64 months range (7-12m). Among them 56 (70\%) were male and 24 (30\%) were female. Regarding antenatal follow up of mother, only $30(37.5 \%)$ mother went for regular antenatal check up and remaining $50(62.55 \%)$ had irregular antenatal check up. But none of them got breastfeeding advice during antenatal visit. Among the respondent's house wife mother was 56 (70\%) and working mother was $24(30 \%)$ and $25(31.25 \%)$ children were born by normal vaginal delivery whereas 55 (68.75\%) children were born by caesarean section delivery (Table -1 ).

\begin{tabular}{|c|c|c|}
\hline Indicators & No & $\%$ \\
\hline \multicolumn{3}{|l|}{ Age of child } \\
\hline 7-12months & 80 & 100 \\
\hline \multicolumn{3}{|l|}{ Sex } \\
\hline Male & 56 & 70 \\
\hline Female & 24 & 30 \\
\hline \multicolumn{3}{|l|}{ Mothers education } \\
\hline Primary & 16 & 20 \\
\hline Secondary & 32 & 40 \\
\hline Higher & 32 & 40 \\
\hline \multicolumn{3}{|l|}{ Father's education } \\
\hline Primary & 16 & 20 \\
\hline Secondary & 16 & 20 \\
\hline Higher & 48 & 60 \\
\hline \multicolumn{3}{|l|}{ Antenatal visit } \\
\hline Regular & 30 & 37.5 \\
\hline Irregular & 50 & 62.5 \\
\hline \multicolumn{3}{|c|}{ Breast feeding education } \\
\hline (during antenatal visit) & 00 & 00 \\
\hline \multicolumn{3}{|l|}{ Mode of delivery } \\
\hline Normal vaginal delivery & 25 & 31.25 \\
\hline Caesarean section & 55 & 68.75 \\
\hline \multicolumn{3}{|l|}{ Mothers occupation } \\
\hline House wife mother & 56 & 70 \\
\hline Working mother & 24 & 30 \\
\hline
\end{tabular}

Regarding feeding pattern of 6 months old infants, breastfeeding was initiated with in 1 hour of birth in 36(45\%) and44 (55\%)mothers after 1hour of birth. Exclusive breastfeeding was found in $40(50 \%)$ children.Breast milk (BM) + formula/ cow's milk was given in $30(37.5 \%)$ children. Only formula milk was given in 10 (12.5\%) children (Table-II).

Table II : Feeding pattern up to 6 mo old infants $(n=80)$

$\begin{array}{lcc}\text { Pattern } & \text { Frequency } & \text { Percent } \\ \text { Initiation of breast feeding } & 36 & 45 \\ <1 \text { hour } & 44 & 55 \\ >\text { 1hour } & 40 & 50 \\ \text { Exclusive breast feeding } & 30 & 37.5 \\ \text { BM + formula/ cow's milk } & & \\ \text { (Mixed feeding) } & 10 & 12.5 \\ \text { Formula milk } & \end{array}$

Relation between early initiation of breast feeding and mode of 
delivery was found that early initiation of breastfeeding was more common in infants delivered by normal vaginal delivery $19(76 \%)$ out of 25 whereas only $17(31 \%)$ out of 55 infants had early initiation of breastfeeding delivered by caesarian section. Regarding mothers education it was found that 20(55.50\%) mothers with higher education initiated breast feeding within 1hr. (Table - III).

Table III : Early initiation ( $<1 \mathrm{hr}$ ) of breast feeding in relation to mode of delivery and mothers education

$\begin{array}{lcc}\text { Variable } & \text { Frequency } & \text { Percent } \\ \text { Mode of delivery } & & \\ \text { Normal vaginal delivery( no 25) } & 19 & 76 \\ \text { Caesarean section (55) } & 17 & 31 \\ \text { Educational status } & & \\ \text { Primary } & 6 & 19.25 \\ \text { Secondary } & 10 & 25.25 \\ \text { Higher } & 20 & 55.50\end{array}$

Rate of exclusive breastfeeding was higher $30(75 \%)$ in children of housewife mother than children of working mothers which was $10(25 \%)$. Here the rate of mixed feeding was $18(60 \%)$ in the children of housewife mother and $12(40 \%)$ was children of working mother. Formula feeding was given in $8(80 \%)$ children of housewife mother and 2(20\%) children of working mother. (Table - IV).

\section{Table IV : Breast feeding status among children of housewife mothers} and working mother

$\begin{array}{lccc}\text { Indicators } & \text { Housewife (56) } & \text { Working (24) } & \text { Total } \\ \text { Exclusive breastfeeding Up to } 6 \text { months } & 30(75 \%) & 10(25 \%) & 40(100 \%) \\ \text { Mixed feeding } & 18(60 \%) & 12(40 \%) & 30(100 \%) \\ \text { Formula milk } & 8(80 \%) & 2(20 \%) & 10(100 \%)\end{array}$

Exclusive breast milk was not given due to job or other occupation in $18(45 \%)$ children whereas $22(55 \%)$ mothercould not give Exclusive breastfeeding (EBF) due to insufficient breast milk (Table: V).

Table V : Reason for not giving exclusive breast feeding(no 40)

$\begin{array}{lcc}\text { Reason } & \text { Frequency } & \% \\ \text { Job/ other occupation } & 18 & 45 \\ \text { Not enough milk } & 22 & 55\end{array}$

\section{Discussion}

Exclusive breast feeding (EBF) is the best recommended infant feeding method for the first six months of life and has a protective effect against child morbidity and mortality. ${ }^{7}$ But it has not yet been universally practiced and the reduction in the rate of EBF is taken as a serious problem, especially in developing countries. $^{8}$

Mean age of children in month was 8.64 months range (7 12months). Among them 56 (70\%) were male and 24 (30\%) were female. Regarding antenatal follow up of mother, only $30(37.5 \%)$ mother went for regular follow up and remaining $50(62.55 \%)$ had irregular antenatal check up. This finding was consistent with the study done by Vafaee $A$ et al. ${ }^{7}$ They showed that regular antenatal visit was $18.2 \%$, Irregular visit was $67.8 \%$ and no visit was $14 \%$.

Regarding breast feeding advice during antenatal visit, present study showed that none of the mother got breastfeeding advice during antenatal visit. This result was not consistent with the result of the study conducted by Vafaee $A$ et al. ${ }^{7}$ they have found that majority $(52 \%)$ of the mothers had received breastfeeding advice during their antenatal visit.

In the present study it was shown that, breastfeeding was initiated with in 1 hour of birth in 36(45\%) mothers and after 1hour of birth in $44(55 \%)$ mothers which was not consistent with the findings conducted by Chakraborty Bet $\mathrm{al}^{8}$ where they found that breastfeeding was initiated with in 1 hour of birth in $68.5 \%$ of the study children (0-23 months). Butit was consistent with a study by Akhtar et al. ${ }^{9}$

Our study showed that early initiation of breastfeeding was more common in infants delivered by normal vaginal delivery $19(76 \%)$ than the infants delivered by caesarian section 17 $(31 \%)$. This finding was similar with the study done by Chakraborty B et al, ${ }^{8}$ where they found that, early initiation of breastfeeding was common in infants delivered by normal vaginal delivery $(72 \%)$ than infants delivered by caesarian section $(68.2 \%)$.

In this study exclusive breastfeeding was found in 40 (50\%) children upto 6 months of age. Breast milk + formula/ cow's milk was given in $30(37.5 \%)$ children. Only formula milk was given in $10(12.5 \%)$ children. This finding was similar with the finding conducted by Chakraborty B et $\left.a\right|^{8}$ where $66.8 \%$ of 0 6 month old children were found to be exclusively breastfed.

In present study rate of exclusive breastfeeding was higher 30 (75\%) among the children of housewife mothers than children of working mothers which was $10(25 \%)$. This study was consistent with the study done by Chakraborty et $a l^{8}$ where the rate of exclusive breastfeeding was found higher (77\%) among the children of housewife mothers than those of working mothers (23\%).

This study showed that $18(45 \%)$ mother could not give exclusive breast milk due to job or other occupation whereas 22 
(55\%) mother cannot give EBF due to insufficient breast milk. Therefore, the speculation of not getting sufficient milk was one of the main reasons for not giving exclusive breastfeeding.

\section{Conclusion}

In the study rate of exclusive breast feeding was $50 \%$. This study also showed that frequency of exclusive breast feeding practice was lower in working mothers than housewife mothers. This study also showed that the speculation of not getting sufficient milk was one of the main reasons for not giving exclusive breastfeeding. Therefore, it is recommended that steps should be taken to improve the existing situation.

\section{References}

1. WHO Collaborative Study Team on the Role of Breastfeeding on the Prevention of Infant Mortality: Effect of breastfeeding on infant and child mortality due to infectious diseases in less developed countries: a pooled analysis. Lancet. 2000, 355: 451-455

2. Black RE, Allen LH, Bhutta ZA, Caulfield LE, de Onis $M$, Ezzati $M$, et al J: Maternal and child undernutrition: global and regional exposures and health consequences. Lancet. 2008, 371: 243-260
3. Black RE, Victora CG, Walker SP, Bhutta ZA, Christian P, de Onis M, Ezzati M, Grantham-McGregor S, Katz J, Martorell R, Uauy R: Maternal and child undernutrition and overweight in low-income and middle-income countries. Lancet. 2013, 382: 427-451.

4. Lande B, Andersen LF, Baerug A, Trygg KU, Lund-Larsen K, Veierod MB, Bjorneboe GE: Infant feeding practices and associated factors in the first six months of life: the Norwegian infant nutrition survey. ActaPaediatr. 2003, 92: 152-161.

5. Tan KL: Factors associated with exclusive breastfeeding among infants under six months of age in peninsular Malaysia. Int Breastfeed J. 2011, 6: 2-10.

6. World health Organization./UNICEF. Global Strategy for Infant and Young Child Feeding 2003.A55/15, Annex-16 April 2002.WHO.

7. Vafaee A, Khabazkhoob M, Moradi A, Najafpoor AA: Prevalence of exclusive breastfeeding during the first six months of life and its determinant factors on the referring children to the health centers in Mashhad, Northeast of Iran. J Appl Sci. 2010, 10: 343-348.

8. Chakraborty B, Rumana J, Begum HA, AfrozaA:Infant and Young Child Feeding Pattern in Children, BANGLADESH J CHILD HEALTH 2016; VOL 40 (2) : 92-97.

9. Akhtar K, Haque ME, Islam MZ, Sharif AI.Feeding Pattern and Nutritional Status of Under Two Years Slum Children. J SaheedShurawardy Med Coll. 2012; 4:3-6.

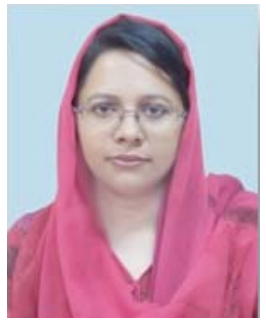

Dr. Farzana Rahman Chowdhury, passed her MBBS from Sir Salimullah Medical College, Mitford, Dhaka in 2002. Then she achieved DCH in 2002 and FCPS in 2012. Since then she is serving in the teaching post in different Non- Government Medical Colleges. She has been serving as Assistant professor in Popular Medical College for 5 years. She has 6 publications in different national medical journals. 